\title{
Stability of High Rockfill Embankment Based on Orthogonal Test and Numerical Simulation
}

\author{
Yanqing ZHANG, Hongjun JING, Jun DAI, Shunfei LI, Zhong ZHANG
}

\begin{abstract}
The parameters of rockfill materials are important factors that influence the stability of high rockfill embankment. However, the influencing laws of parameter changes on the deformation of high rockfill embankments still remain unknown. To deepen understanding on the influencing laws of parameters of rockfill materials on the stability of high rockfill embankment, a case study using an orthogonal test and numerical simulation was conducted on the high rockfill embankment with 50.6 m banking in the secondary road reconstruction project of the national highway 316 from Xunyang to Ankang in the Shaanxi Province of China. The influences of elasticity modulus, dry density, Poisson's ratio, frictional angle, and cohesion on the stability of high rockfill embankment were analyzed. A three-dimensional numerical model of high rockfill embankment was constructed using FLAC3D, and a numerical simulation of the embankment deformation was performed using the maximum settlement of embankment as the evaluation index. The influences of different factors on the deformation of high rockfill embankment were evaluated through a numerical simulation based on the orthogonal test to verify the accuracy of the orthogonal test. In addition, the deformation law of high rockfill embankment was examined. Research results demonstrate that dry density predominantly influences the stability of high rockfill embankment, followed by elasticity modulus, Poisson's ratio, cohesion, and frictional angle. The optimal combination of parameters of rockfill materials was concluded from further analysis. The numerical simulation and orthogonal test results are consistent. The top surface of the high rockfill embankment develops settlement deformation during the construction period, accompanied by outward lateral squeezing trend at the foot of slope. The vertical deformation consists of settlement first and then upheaval. Research conclusions can provide some references for the reasonable selection of rockfill materials for embankment and the stability analysis of high rockfill embankment.
\end{abstract}

Keywords: high rockfill embankment; numerical simulation; orthogonal test; road engineering; stability

\section{INTRODUCTION}

The continuous building of highways in mountain areas has facilitated the construction of many high embankments. Stability analysis of high rockfill embankment has attracted wide attention. Such stability analysis is an old and complicated topic. In the early stage, the stability of high rockfill embankment has been analyzed through soil mechanics, material mechanics, homogeneous elasticity, and elastic-plastic theory by the semi-experience and semi-theoretical method. Outstanding progresses on studies on stability analysis of embankment have been achieved through unremitting endeavours of scholars in the world. Currently, stability analysis of embankment can be generally divided into ultimate equilibrium analysis method [1, 2], random theoretical analysis method $[3,4]$, numerical analysis method $[5,6]$, and neural network algorithm [7, 8] according to theoretical bases and analysis principles.

The ultimate equilibrium analysis method is accepted as a practical technique for evaluating the stability of roadbed slope due to its simple calculation model and easy calculation scheme. However, this method requires the position and shape of the sliding surface to establish an equilibrium equation for solving the stability coefficient of roadbed slope. Conversely, the random theoretical analysis method avoids some uncertain factors that influence the stability of roadbed slope and can analyze the stability of embankment macroscopically. However, the results of random theoretical analysis have poor accuracy. With the development of computer technology, the numerical analysis method provides a convenient and effective means to analyze the stability of embankment. Numerical analysis can provide an intuitive understanding on the stress-strain state of embankment and the development of plastic zones. However, the numerical analysis results are restricted by the constitutive relations of rockfill materials. Neural network has strong nonlinear dynamic processing ability and can realize nonlinear mapping without knowing the relationship between distribution form of data and variables. The neural network algorithm ignores random and fuzzy factors that can influence the stability of embankment. Neural network can quickly evaluate the stability of roadbed slope but has high requirements on the completeness of data. Different methods also have different application ranges and advantages and disadvantages, but none of them can ignore the physical and mechanical properties of rockfill materials.

The parameters of rockfill materials are based on the stability analysis of high rockfill embankment. Such stability is directly related to the physical and mechanical parameters of rockfill materials, environmental conditions, and loads. The buckling failure of high rockfill embankment arises from factors originating from multiple aspects, including hydrogeological conditions, physical and mechanical properties of rockfill materials, construction technologies, and design theory. The buckling failure of high rockfill embankment is caused by poor understanding of the failure mechanism and the importance of stability analysis. Therefore, studying the stability of high rockfill embankment is crucial to assure the long-term stable operation of high-level highways in mountain areas.

On this basis, this study explored the influencing law of parameters of rockfill materials on the stability of high rockfill embankment through orthogonal test and numerical simulation to provide references for the reasonable selection of rockfill for embankment and deepen understanding on the influencing laws of parameters on the deformation of embankment. Research conclusions can provide references for the stability analysis of the national highway 316 projects and other similar engineering projects in China. 


\section{STATE OF THE ART}

Given the lack of excellent soil rockfill for building highways in mountain regions, the roadbeds are mainly filled with waste slag produced from the cutting and excavation of tunnels. High rockfill embankment has become a common roadbed form in high-level highways to fully utilize the excellent performance of waste slag and decrease the influences of waste slag on ecological environmental failure along highways and traveling safety of the public. The stability of high rockfill embankment also attracts considerable attention from the engineering circle. Relevant scholars have conducted many studies on such stability.

Some scholars have analyzed the stability of high embankment through experiments. Kohgo et al. [9] examined the influences of water level variation on the stability of rockfill embankment in reservoir areas by using a centrifugal model. Their analysis results are sensitive to the parameters of rockfill. Cao et al. [10] experimentally studied the stability of loess-filled high embankment under different boundary conditions (flexible and rigid) by applying the centrifugal model and ignoring the characteristics of rockfill. Enomoto et al. [11] conducted a series of dynamic centrifugal model tests by exploring the influences of water level, embankment height, slope height, compaction degree, and rockfill on the anti-seismic properties of embankment (mainly soil embankment). Boulanger et al. [12] investigated the anti-seismic performance of high embankment with easy liquefaction foundation reinforced by cement-soil walls by using centrifugal model test and numerical simulation. However, numerical simulation has some limitations in reflecting liquefaction and cracking of soils. Although model test results have some limitations, they provide convenience in studying high embankment projects and experimental references for people to solve high embankment deformation. However, these experiments are generally costly.

Field test is another way to examine the stability of embankment. $\mathrm{Xu}$ et al. [13] comparatively studied the long-term deformation of rockfill embankment under heavy loads through field creep test and numerical simulation, and the results are sensitive to the surrounding environment. Cao et al. [14] designed a large field test and studied the deformation behaviours of embankment under the reinforcement of geogrids and supports of floating piles, but the test period is generally limited. The field test can observe the deformation behaviour of embankment, but the test period is lengthy and the test results are sensitive to environmental changes.

Other scholars have investigated the stability of embankment in regions with complicated geographic and climatic environments, thereby expanding the knowledge on high rockfill embankment. On the basis of field plate loading test, triaxial creeping test, and monitoring data analysis, Gan et al. [15] proposed a comprehensive study method of the stress and deformation of high rockfill embankment. They also analyzed and predicted the longterm deformation characteristics of embankments with complicated geography and geological features. However, the results are closely related to the constitutive model and parameters of rockfill. $\mathrm{Yu}$ et al. [16] performed field monitoring on the settlements of different soil layers in an embankment in permafrost regions, analyzed the characteristics of embankment settlement under different geological conditions, and discussed the influences of temperature changes on the settlement deformation of embankments. However, the infrastructure at top of the embankment can influence long-term deformation of embankment to some extent.

Studies on the stability of high rockfill embankment accumulate numerous experimental data and engineering experiences for a similar type of engineering. Many scholars have proposed prediction models for the settlement deformation of high rockfill embankment by using existing engineering data. However, these prediction models have limits of applications. With considerations to characteristics of soft soil and various geometric parameters of embankment, Chik et al. [17] proposed a method to predict settlement deformation of embankment under loads by using the artificial neutral network system. This approach is highly applicable to soft soil foundation. Sukkarak et al. [18] improved the elastic-plastic model of double yield surfaces based on the hardening soil model and simulated the settlement deformation of high rockfill embankment during the construction period. The results demonstrated that the predicted settlement deformation conforms well to field monitoring data. On the basis of the predicted post-construction settlement of high rockfill foundation in Lüliang Airport in China, Zhu et al. [19] analyzed the post-construction components of the original foundation and filling structure and the causes of differential settlement and proposed a recursive analysis method of post-construction settlement based on strain rate. This method has large errors in the early construction period of embankment. Miščević et al. [20] developed a calculation model to predict the additional settlement of embankment caused by alteration of rockfill and expanded the knowledge range on settlement deformation of embankment for solving the additional settlement of embankment caused by the worsening of soft rockfill. Zhang et al. [21] put forward a practical calculation technique that can predict the deformation of embankment under long-term traffic loads based on the theory of equivalent viscoelastoplastic model. This method is only applicable for estimating the settlement of embankment and cannot calculate the horizontal deformation of embankment.

To solve the shortcomings of existing studies, this work explores the deformation law of high rockfill embankment in the $\mathrm{K} 21+350-\mathrm{K} 21+541.751$ section of the secondary road reconstruction project of the national highway 316 from Xunyang to Ankang in Shaanxi Province under different parameters of rockfill materials through orthogonal test and numerical simulation. This study is expected to expand the knowledge range on high rockfill embankment. The conclusions can provide references for material selection and stability analysis of high rockfill embankment in the Qinba Mountain area and other regions in China.

The remainder of this study is organized as follows. Section 3 elaborates the orthogonal test and numerical simulation design. Section 4 analyzes and discusses the results of the orthogonal test and numerical simulation. Section 5 summarizes the conclusions of this work. 


\section{METHODOLOGY}

\subsection{Orthogonal Test Design}

Univariate or binary analysis of variance can be used to analyze the significance of the effects of one or two factors on the test results in practical situations. The stability analysis of high rockfill embankment must consider the effects of multiple factors on deformation and can be realized by orthogonal test.

Orthogonal test is a mathematical statistics method that arranges the tests and analyzes the results scientifically by using the orthogonal table. This approach selects few test schemes with strong representativeness from abundant test conditions and then recognizes the optimal scheme by analyzing the few test schemes. Moreover, information on relevant factors is provided. Test results are generally test indexes. Conditions that can be investigated or controlled in tests are elements or factors. Different states of elements in the test are called levels.

According to the given levels of elements and factors for investigation, the corresponding orthogonal table $L_{n}\left(r_{1}\right.$ $\left.\times r_{2} \times \cdots \times r_{m}\right)$ is chosen, where $L$ is the orthogonal table, $n$ is the number of rows in the orthogonal table (this means $n$ tests can be arranged), and $m$ is the number of columns in the orthogonal table (the most number of factors that can be arranged in the test). The factor $j$ has $r_{j}$ levels. An isohorizontal orthogonal table is commonly used: $r_{1}=r_{2}=$ $\cdots=r_{m}=r$, which is recorded as $L_{n}\left(r^{m}\right)$.

Parameters are expressed as follows: different factors are $A, B, \ldots$; the number of levels of different factors is $r$; $A_{i}$ expresses the level $i$ of element $A(i=1,2, \ldots, r)$, and $X_{i j}$ reflects the value of level $i$ of element $j(i=1,2, \ldots, r ; j=$ $A, B, \ldots)$
If the test result index of the level $i$ of element $j$ in the test under $X_{i j}$ is $Y_{i j}$ (which is a random variable following normal distribution), then $n$ test results $Y_{i j k}(k=1,2, \ldots, n)$ can be gained from $n$ tests under $X_{i j}$. Relevant calculation parameters are shown as follows:

$K_{i j}=\sum_{k=1}^{n} Y_{i j k}$

Range $\left(R_{j}\right)$ is used as the parameter to evaluate the sensitivity of elements and can be expressed as

$$
R_{j}=\max \left\{K_{1 j}, K_{2 j}, \ldots, K_{r j}\right\}-\min \left\{K_{1 j}, K_{2 j}, \ldots, K_{r j}\right\}
$$

The element highly influences the test results when $R_{j}$ is high. In other words, the sensitivity of the element is strong. Elements with low $R_{j}$ can be viewed as insignificant to the test results when it changes within the chosen range.

In this study, five elements are chosen, namely, elasticity modulus $(A)$, dry density $(B)$, Poisson's ratio $(C)$, frictional angle $(D)$, and cohesion $(E)$. The influences of the five elements on the stability of high rockfill embankment are investigated. The levels of each element are determined with references to the parameters of local common rockfill materials. The five elements and their corresponding levels are shown in Tab. 1. The orthogonal table of five elements and four levels are listed in Tab. 2. A total of 16 groups of tests are performed according to the orthogonal test design table $L_{16}\left(4^{5}\right)$.

Table 1 Elements and their levels in the orthogonal test

\begin{tabular}{|c|c|c|c|c|c|}
\hline \multirow{2}{*}{ Level } & \multicolumn{4}{|c|}{ Factors } \\
\cline { 2 - 6 } & $A$ (elasticity modulus) / MPa & $B$ (dry density) $/ \mathrm{kg} / \mathrm{m}^{3}$ & $C$ (Poisson's ratio) & $D$ (frictional angle) / ${ }^{\circ}$ & 26.1 \\
\hline 1 & 65.5 & 1710 & 0.25 & 30.1 & 20.8 \\
\hline 2 & 75.5 & 2110 & 0.33 & 32.8 & 34.1 \\
\hline 3 & 85.5 & 2410 & 0.40 & 34.8 & 38.1 \\
\hline 4 & 95.5 & 2610 & 0.45 & 93.8 \\
\hline
\end{tabular}

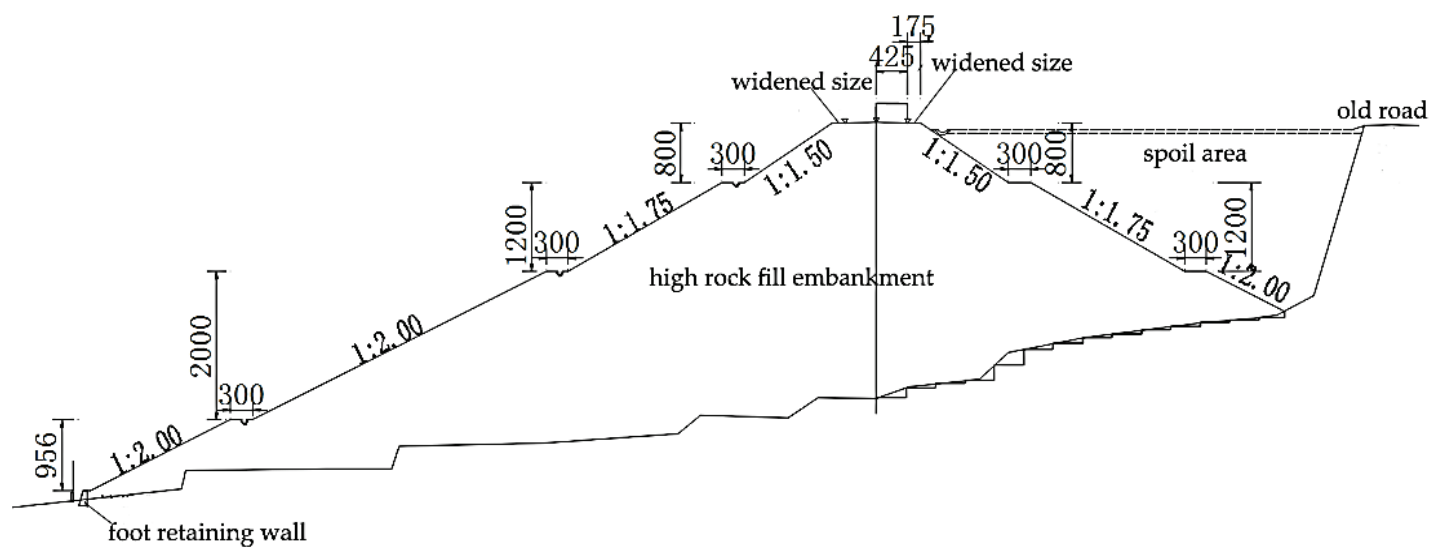

Figure 1 Section diagram of the maximum filling height / $\mathrm{mm}$

\subsection{Numerical Simulation}

According to the section of the maximum filling height $(50.6 \mathrm{~m})$ in this high rockfill embankment (Fig. 1), a threedimensional numerical simulation model (Fig. 2) was constructed using the FLAC3D software. This model was divided into 17.732 nodes and 30.470 units. The rock-soil mass applied the Mohr-Coulomb model, and the filling process of embankment was accomplished in 26 steps. The bottom side and sides of embankment were constrained boundaries, and the upper surface was a free surface. In this section of embankment, the maximum filling height in the 
center was $37.2 \mathrm{~m}$, and the maximum height of the roadbed slope was $50.6 \mathrm{~m}$. The first-level slope rate was $1: 1.5$, and the slope height was $8 \mathrm{~m}$. A $3 \mathrm{~m}$-wide platform was set. The second-level slope rate and slope height were 1:1.75 and $12 \mathrm{~m}$, and a $3 \mathrm{~m}$-wide platform was set. The third-level slope rate and slope height were set 1:2 and $20 \mathrm{~m}$, and a 3 $\mathrm{m}$-wide platform was set. The fourth-level slope rate was chosen as 1:2.

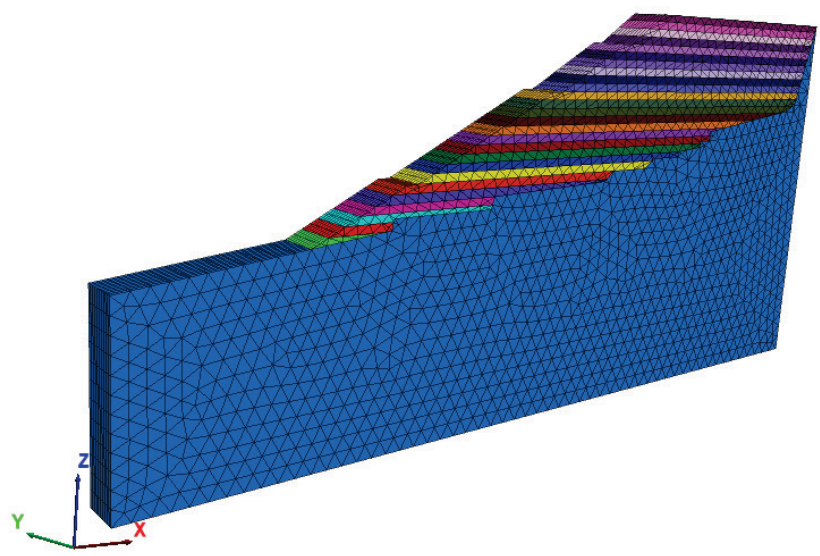

Figure 2 Calculation model of the high rockfill embankment

\section{RESULT ANALYSIS AND DISCUSSION 4.1 Analysis of Orthogonal Test Results}

In this study, the maximum settlement of the embankment was chosen as the index of the orthogonal test and the settlement of the embankment was analyzed using the FLAC3D software. The orthogonal test design and calculation results are listed in Tab. 2. Sensitivity was analyzed according to Tab. 2 and Eqs. (1) and (2). The results are listed in Tab. 3.

Tabs. 2 and 3 indicate that the dry density of rockfill primarily influences the stability of high rockfill embankment, followed by elasticity modulus, Poisson's ratio, cohesion, and frictional angle. According to range analysis, dry density is an important element that influences the stability of high rockfill embankment. Therefore, the moisture content of rockfill and the compaction degree of embankment should be controlled during construction. Further analysis of data in Tab. 3 reveals that the beneficial production condition is $A_{4} B_{1} C_{4} D_{3} E_{1}$ with respect to the five elements and four levels, and the condition achieves the minimum settlement of embankment. On the contrary, the disadvantageous production condition is $A_{1} B_{4} C_{1} D_{2} E_{3}$, which causes the maximum settlement of embankment.

Table 2 Orthogonal test design and calculation results

\begin{tabular}{|c|c|c|c|c|c|c|}
\hline NO. & $A / \mathrm{MPa}$ & $B / \mathrm{kg} / \mathrm{m}^{3}$ & $C$ & $D /{ }^{\circ}$ & $E / \mathrm{kPa}$ & $\begin{array}{c}\text { Maximum settlement of } \\
\text { embankment / m }\end{array}$ \\
\hline 1 & 65.5 & 1710 & 0.25 & 26.1 & 20.8 & 0.30331 \\
\hline 2 & 65.5 & 2110 & 0.33 & 30.1 & 32.8 & 0.37323 \\
\hline 3 & 65.5 & 2410 & 0.40 & 34.1 & 64.8 & 0.42469 \\
\hline 4 & 65.5 & 2610 & 0.45 & 38.1 & 93.8 & 0.45872 \\
\hline 5 & 75.5 & 1710 & 0.33 & 34.1 & 93.8 & 0.30082 \\
\hline 6 & 75.5 & 2110 & 0.25 & 38.1 & 64.8 & 0.37228 \\
\hline 7 & 75.5 & 2410 & 0.45 & 26.1 & 32.8 & 0.42132 \\
\hline 8 & 75.5 & 2610 & 0.40 & 30.1 & 20.8 & 0.45785 \\
\hline 9 & 85.5 & 1710 & 0.40 & 38.1 & 32.8 & 0.29900 \\
\hline 10 & 85.5 & 2110 & 0.45 & 34.1 & 20.8 & 0.36729 \\
\hline 11 & 85.5 & 2410 & 0.25 & 30.1 & 93.8 & 0.42333 \\
\hline 12 & 85.5 & 2610 & 0.33 & 26.1 & 64.8 & 0.45718 \\
\hline 13 & 95.5 & 1710 & 0.45 & 30.1 & 64.8 & 0.29657 \\
\hline 14 & 95.5 & 2110 & 0.40 & 26.1 & 93.8 & 0.36771 \\
\hline 15 & 95.5 & 2410 & 0.33 & 38.1 & 20.8 & 0.42053 \\
\hline 16 & 95.5 & 2610 & 0.25 & 34.1 & 32.8 & 0.45664 \\
\hline
\end{tabular}

Table 3 Multi-element sensitivity analysis

\begin{tabular}{|c|c|c|c|c|c|}
\hline Elements & $A / \mathrm{MPa}$ & $B / \mathrm{kg} / \mathrm{m}^{3}$ & $C$ & $D /{ }^{\circ}$ & $E / \mathrm{kPa}$ \\
\hline$K_{1 j}$ & 1.55995 & 1.19970 & 1.55556 & 1.54952 & 1.54898 \\
\hline$K_{2 j}$ & 1.55227 & 1.48051 & 1.55176 & 1.55098 & 1.55019 \\
\hline$K_{3 j}$ & 1.54680 & 1.68987 & 1.54925 & 1.54944 & 1.55072 \\
\hline$K_{4 j}$ & 1.54145 & 1.83039 & 1.54390 & 1.55053 & 1.55058 \\
\hline Range & 0.01850 & 0.63069 & 0.01166 & 0.00146 & 0.00174 \\
\hline Sensitivity & \multicolumn{5}{|c|}{$B>A>C>E>D$} \\
\hline
\end{tabular}

\subsection{Analysis of Numerical Simulation Results}

According to the orthogonal test results, dry density, elasticity modulus, and Poisson's ratio are the three main influencing elements of the stability of high rockfill embankment. The influencing laws of dry density, elasticity modulus, and Poisson's ratio on stability of high rockfill embankment were analyzed through a numerical simulation using FLAC3D (other parameters were consistent with those in level 2). In addition, embankment deformation behaviours under advantageous and disadvantageous conditions were compared through numerical analysis. The deformation curve of embankment under different dry densities is shown in Fig. 3.

Fig. 3 shows that the deformation behaviour of embankment changes significantly with the variation in dry density. With the increase in dry density, the maximum settlement of embankment increases continuously, and the $X$-direction displacement at the slope foot is mainly negative and increases continuously. Meanwhile, negative and positive $Z$-direction displacements increase. As the filling height increases, the maximum settlement and the negative $X$-direction displacement present a linear growth trend. In the $Z$-direction, the slope foot develops settlement 
first and then upheaval with the increase in filling height. The deformation intensifies gradually. Within the chosen range of dry density, the changes in dry density influence deformation of embankment throughout the construction period significantly.

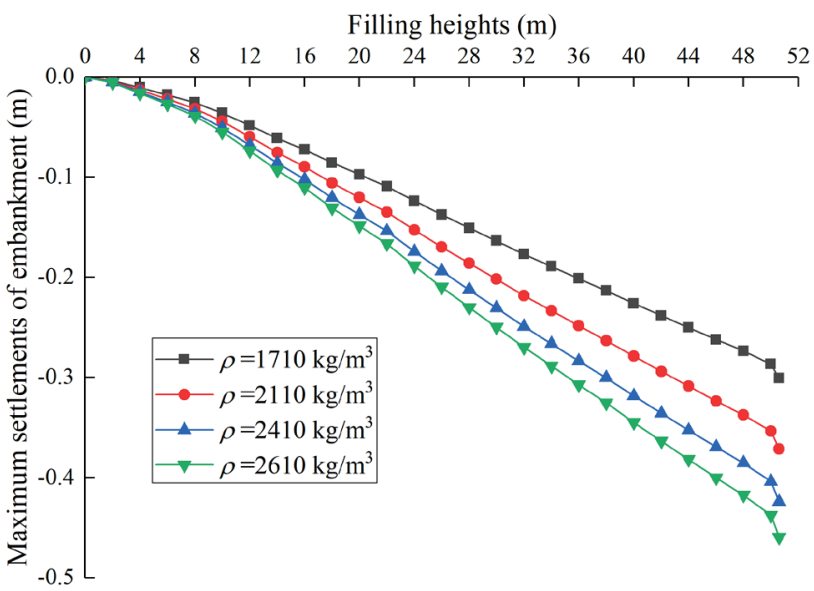

(a) Variation curves of the maximum settlement with filling height

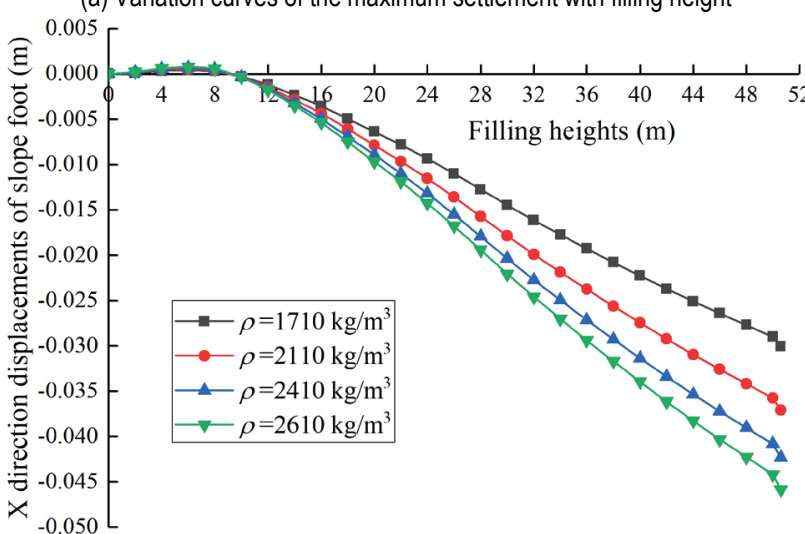

(b) Variation curves of the $X$-direction displacement at the slope foot with filling height

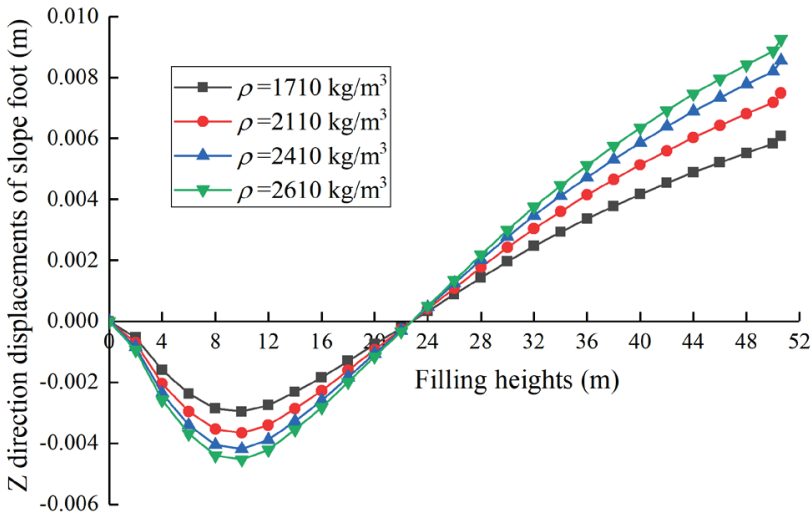

(c) Variation curves of the Z-direction displacement at the slope foot with filling height

Figure 3 Deformation curves of embankment under different dry densities

The deformation curves of embankment under different elasticity moduli are shown in Fig. 4.

Fig. 4 indicates that the deformation behaviours of embankment under different elasticity moduli are relatively similar. The variation trends of maximum settlement, $X$-direction displacement, and $Z$-direction displacement of the embankment are consistent with those under different dry conditions. In the chosen range of elasticity modulus, the deformation of embankment throughout the construction period remains constant with the changes in elasticity modulus.

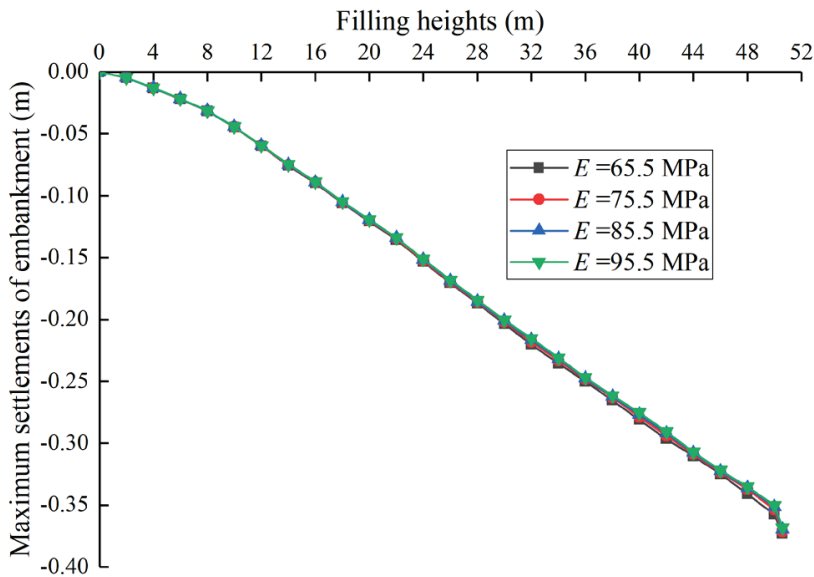

(a) Variation curves of the maximum settlement with filling height

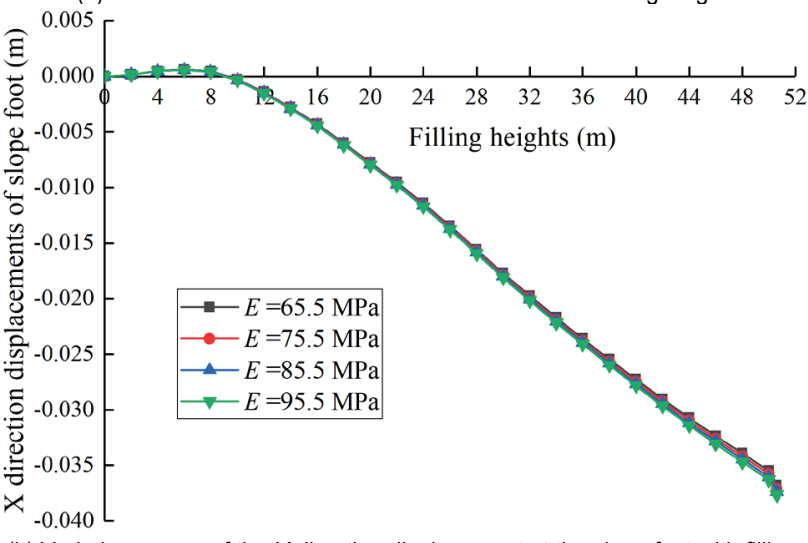

(b) Variation curves of the $X$-direction displacement at the slope foot with filling

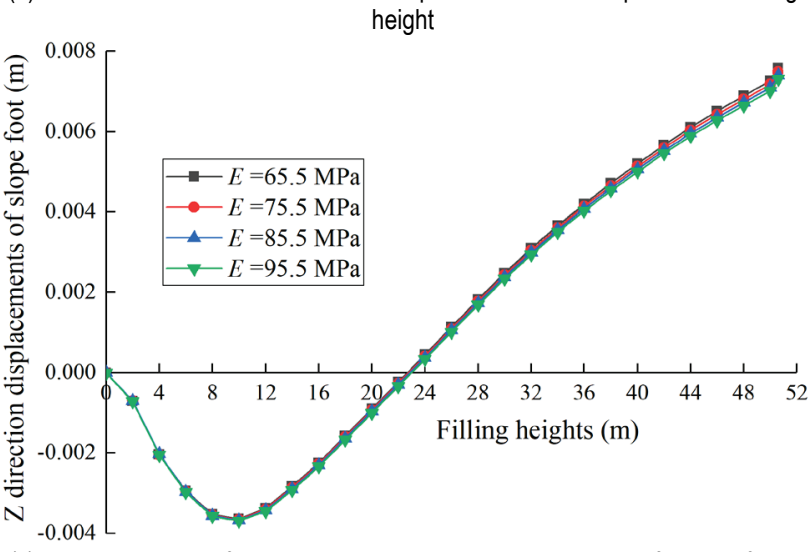

(c) Variation curves of the Z-direction displacement at the slope foot with filling height

Figure 4 Deformation curves of embankment under different elasticity moduli

The deformation curves of embankment under different Poisson's ratios are shown in Fig. 5.

As shown in Fig. 5, the maximum settlement of embankment remains constant with the changes in Poisson's ratio. The $X$ - and $Z$-direction displacements at the slope foot are similar in the beginning of the construction period, but they begin to diverge in the late stage. The variation trends of the maximum settlement, $X$-direction displacement, and $Z$-direction displacement are similar with those under different dry densities. In the chosen range of Poisson's ratio, Poisson's ratio insignificantly affects the maximum settlement of embankment but 
significantly influences the displacements at the slope foot in the late stage of construction.

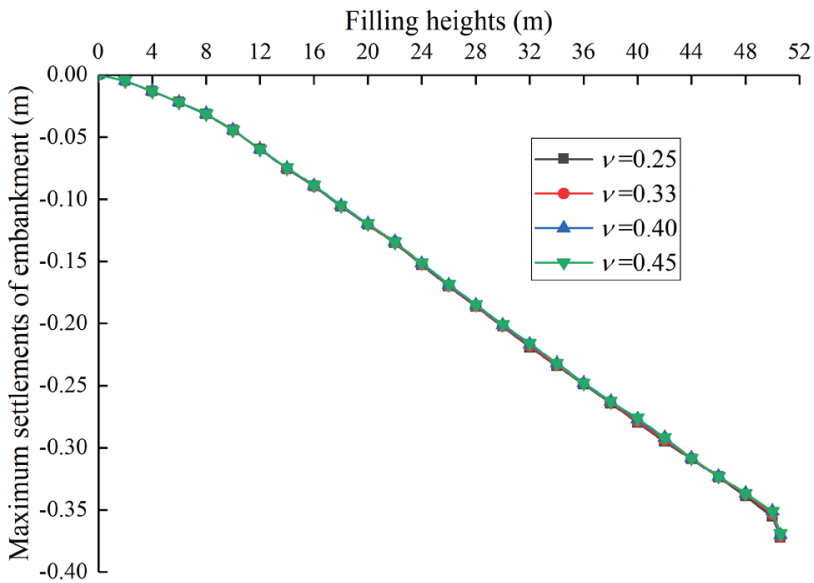

(a) Variation curves of the maximum settlement with filling height

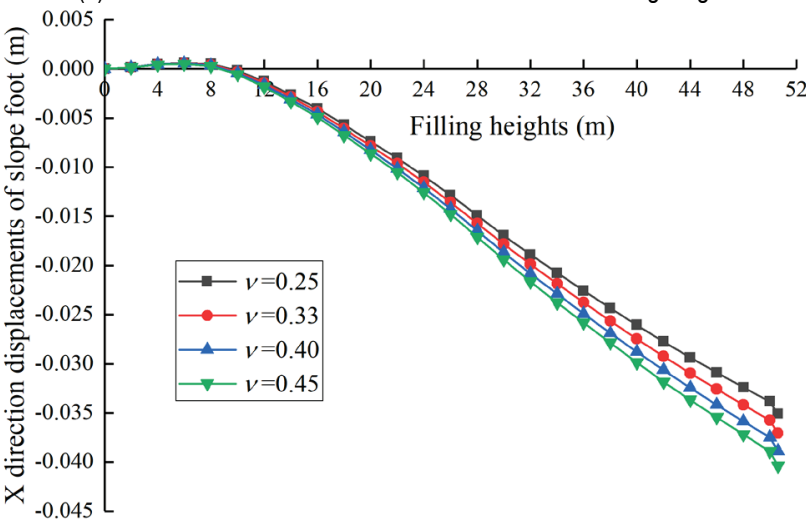

(b) Variation curves of the $X$-direction displacement at the slope foot with filling

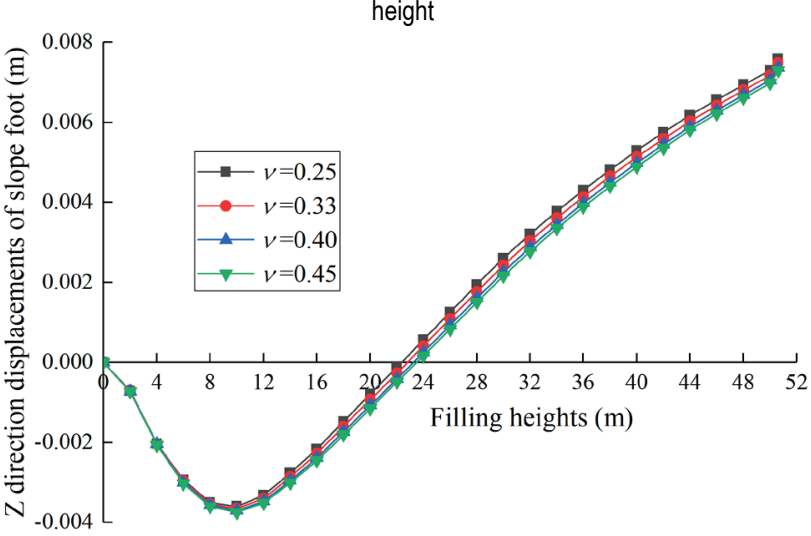

(c) Variation curves of the Z-direction displacement at the slope foot with filling height

Figure 5 Deformation curves of embankment under different Poisson's ratios

The deformation curves of embankment under advantageous and disadvantageous combinations are shown in Fig. 6.

Fig. 6 shows that the deformation behaviours at the top surface and the slope foot of the embankment are positively related to the filling height under advantageous and disadvantageous conditions $\left(A_{4} B_{1} C_{4} D_{3} E_{1} \quad\right.$ and $A_{1} B_{4} C_{1} D_{2} E_{3}$ ). By contrast, the deformation of embankment under the advantageous condition increases slowly with the increase in filling height and has small volume. Under the chosen levels of elements, the deformation of high rockfill embankment under advantageous condition is approximately $30 \%$ less than that under the disadvantageous condition.
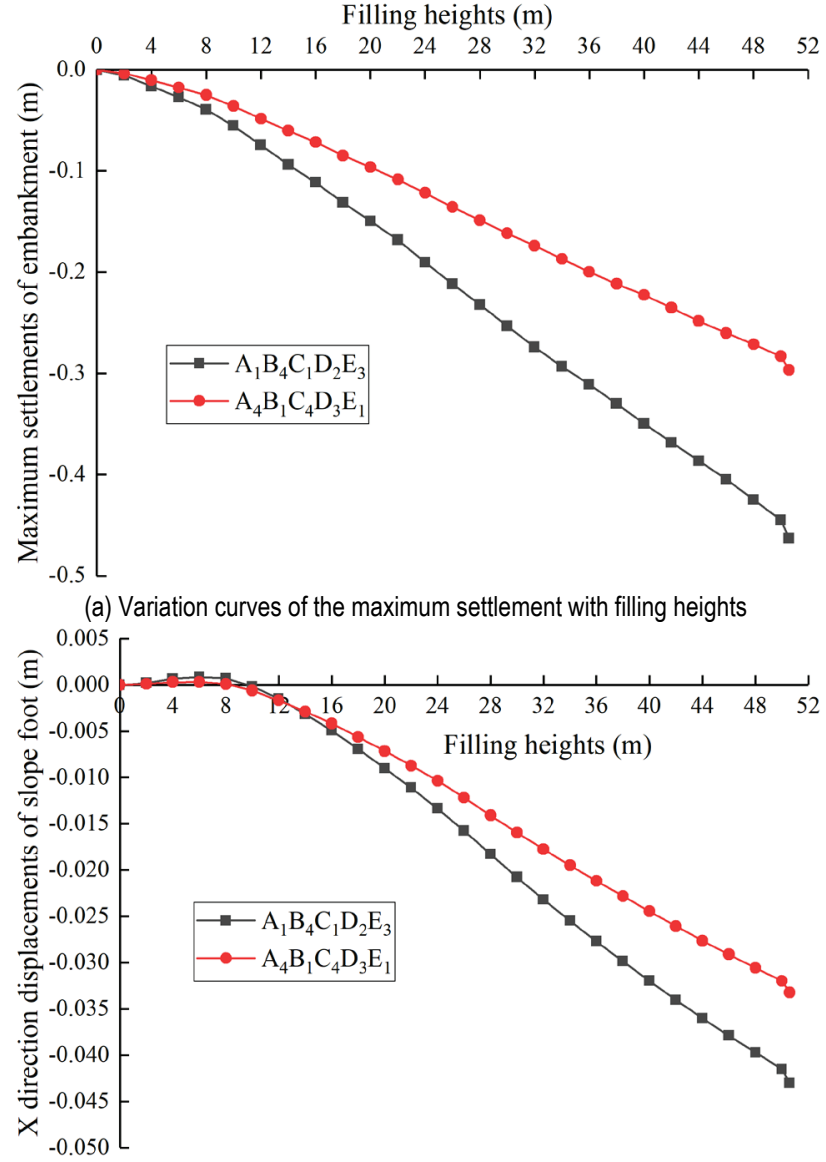

(b) Variation curves of the $X$-direction displacement at the slope foot with filling height

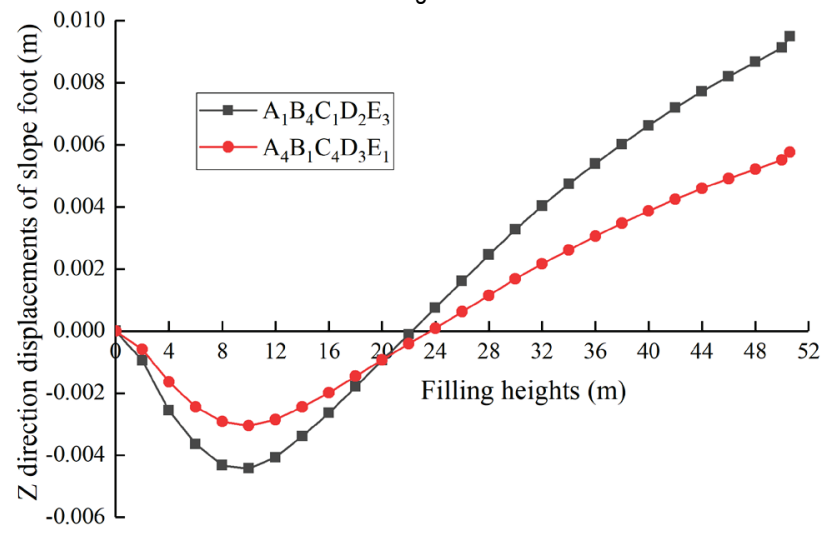

(c) Variation curves of the Z-direction displacement at the slope foot with filling height

Figure 6 Deformation curves of embankment under advantageous and disadvantageous conditions

\subsection{Deformation Laws of High Rockfill Embankment}

The settlement law of high rockfill embankment is analyzed by taking level 2 as an example.

The cloud map of variation in settlement with filling height is shown in Fig. 7. Evidently, the settlement of embankment increases continuously with the increase in filling height, and the range expands gradually. When the construction of embankment is completed, the maximum settlement occurs at the center of the embankment. The deformation at the slope foot is mainly controlled by upheaval. In addition, the deformation and range increase continuously with the increase in filling height. 


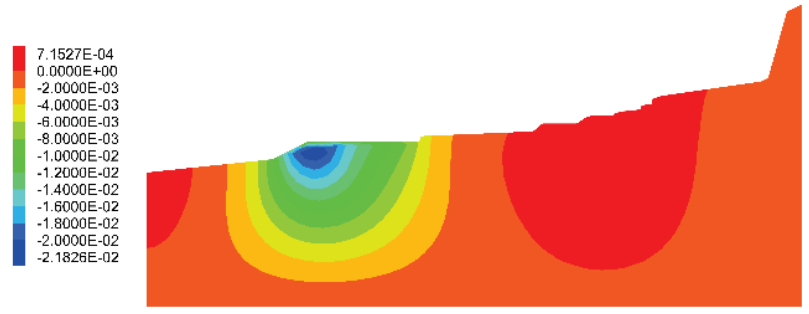

(a) Cloud map of the settlement of embankment when the filling height is $6 \mathrm{~m}$

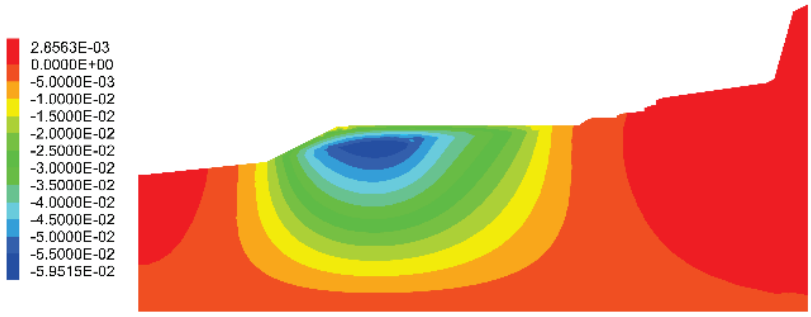

(b) Cloud map of embankment settlement when the filling height is $12 \mathrm{~m}$

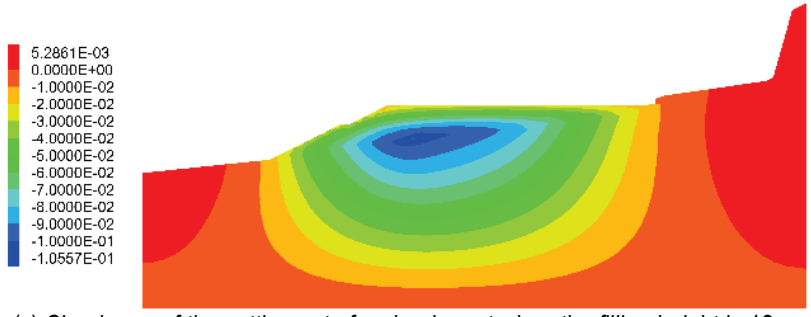

(c) Cloud map of the settlement of embankment when the filling height is $18 \mathrm{~m}$

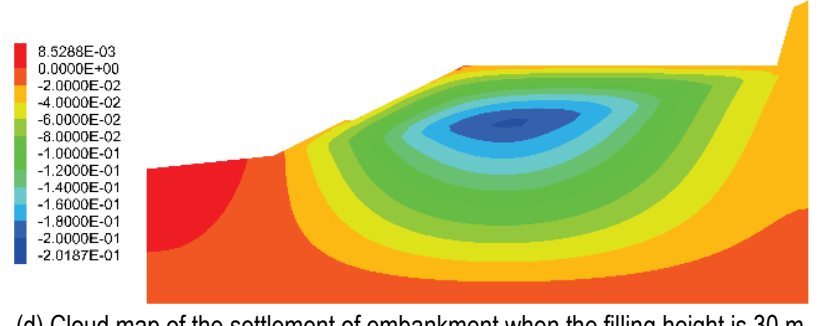

(d) Cloud map of the settlement of embankment when the filling height is $30 \mathrm{~m}$

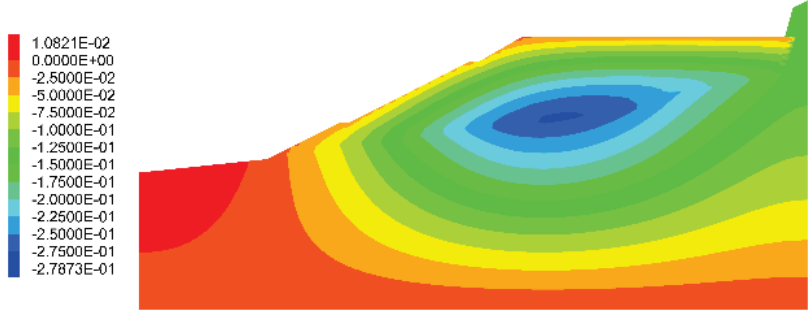

(e) Cloud map of the settlement of embankment when the filling height is $40 \mathrm{~m}$

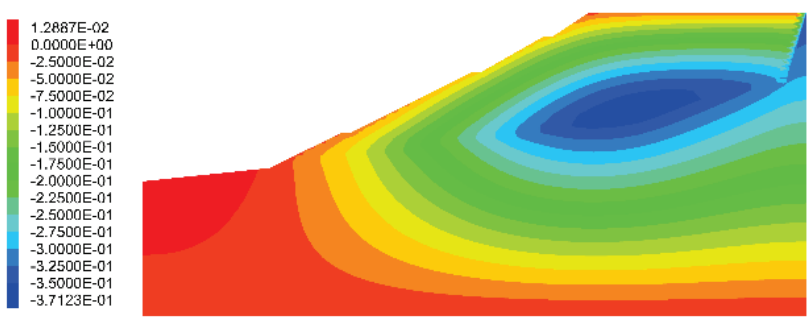

(f) Cloud map of the settlement of embankment when the filling height is $50.6 \mathrm{~m}$

Figure 7 Variations in the settlement of embankment with filling height

The cloud maps of the changes in $X$-direction deformation with filling height are shown in Fig. 8. Clearly, positive and negative $X$-direction displacements are at two sides of the embankment. The maximum positive displacement occurs in the rock layer below the embankment, while the maximum negative displacement occurs in the rock layer below the slope foot. With the increase in filling height, the maximum positive and negative displacements move toward the right side of embankment and expand continuously to the surrounding areas. When the embankment construction is completed, negative displacement takes the dominant role in the deformation of the whole embankment and the maximum negative displacement appears in the rock layer below the third-level slope.

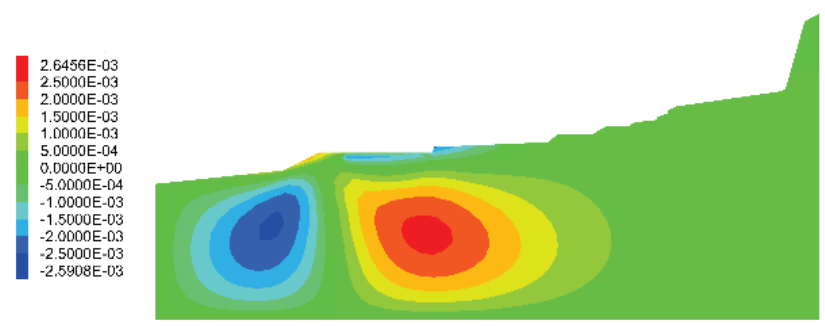

(a) Cloud map of the $X$-direction displacement when the filling height is $6 \mathrm{~m}$

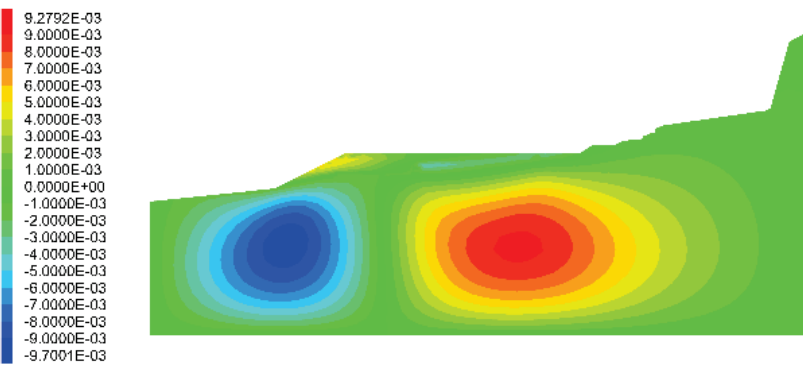

(b) Cloud map of the $X$-direction displacement when the filling height is $12 \mathrm{~m}$

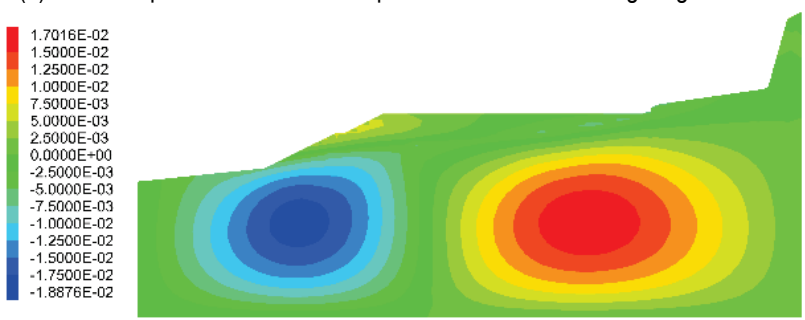

(c) Cloud map of the $X$-direction displacement when the filling height is $18 \mathrm{~m}$

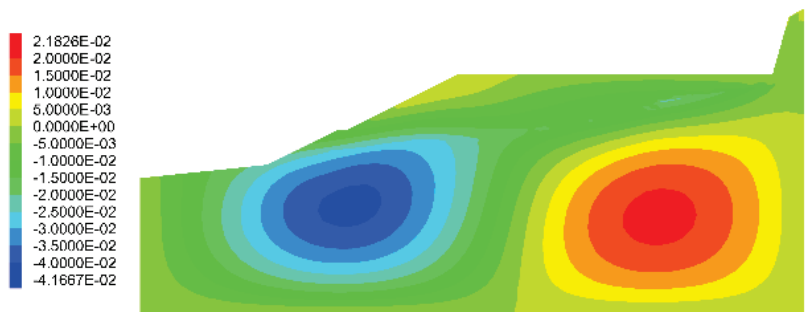

(d) Cloud map of the $X$-direction displacement when the filling height is $30 \mathrm{~m}$

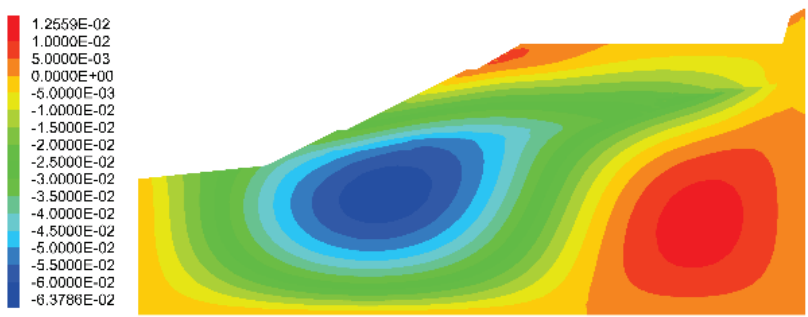

(e) Cloud map of the $X$-direction displacement when the filling height is $40 \mathrm{~m}$

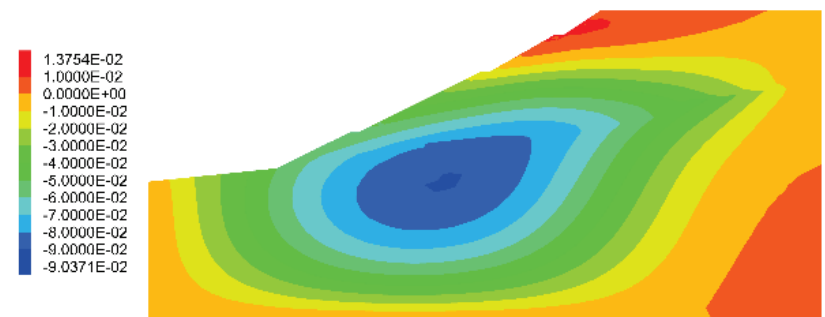

(f) Cloud map of the $X$-direction displacement when the filling height is $50.6 \mathrm{~m}$ Figure 8 Variations in the $X$-direction displacement with filing height 


\section{CONCLUSIONS}

The effects of different rockfill parameters on the stability of high rockfill embankment were analyzed through an orthogonal analysis to understand the deformation law of high rockfill embankment comprehensively. On this basis, the settlement law of high rockfill embankment was explored using a numerical simulation. The following major conclusions were drawn:

(1) Among five selected elements, the orthogonal test reveals that dry density primarily influences the stability of high rockfill embankment, followed by elasticity modulus, Poisson's ratio, cohesion, and frictional angle.

(2) The influencing laws of different elements on the deformation behaviour of high rockfill embankment are disclosed from numerical simulation. The dry density of rockfill can significantly affect the settlement of the embankment and the deformation at the slope foot, whereas the elasticity modulus influences the deformation of embankment slightly. Poisson's ratio slightly affects the settlement of embankment but significantly influences the horizontal deformation of the slope foot.

(3) The top surface of high rockfill embankment develops a settlement deformation during the construction, which is accompanied by outward horizontal squeezing at the slope foot. The vertical deformation is manifested by settlement first and then upheaval.

The current study conclusions can provide some test references for the reasonable selection of rockfill and the stability analysis of high rockfill embankment. However, the stability of high rockfill embankment is controlled by multiple aspects. This study only focuses on the parameters of rockfill but ignores other elements and the combination of multiple factors. Static and dynamic stabilities of high rockfill embankment under multiple elements can be compared in future studies to expand the knowledge range of high rockfill embankment and provide references for comprehensive studies on the deformation mechanism of high rockfill embankment.

\section{Acknowledgements}

This study was supported by the National Natural Science Foundation of China (Grant No. 51174159).

\section{REFERENCES}

[1] Rabie, M. (2016). Performance of hybrid MSE/Soil Nail walls using numerical analysis and limit equilibrium approaches. Housing and Building National Research Center Journal, 12, 63-70. https://doi.org/10.1016/j.hbrcj.2014.06.012

[2] Agam, M. W., Hashim, M. H. M., Murad, M. I., \& Zabidi, H. (2016). Slope sensitivity analysis using Spencer's Method in comparison with general limit equilibrium method. Procedia Chemistry, 19, 651-658. https://doi.org/10.1016/j.proche.2016.03.066

[3] Johari, A. \& Khodaparast, A. R. (2015). Analytical stochastic analysis of seismic stability of infinite slope. Soil Dynamics and Earthquake Engineering, 79, 17-21. https://doi.org/10.1016/j.soildyn.2015.08.012

[4] Napoli, L. M., Barbero, M., Ravera, E., \& Scavia, C. (2018). A stochastic approach to slope stability analysis in bimrocks. International Journal of Rock Mechanics and Mining Sciences, 101, 41-49. https://doi.org/10.1016/j.jijmms.2017.11.009

[5] Zhou, X. P., Zhao, Y., \& Qian, Q. H. (2015). A novel meshless numerical method for modeling progressive failure processes of slopes. Engineering Geology, 192, 139-153. https://doi.org/10.1016/j.enggeo.2015.04.005

[6] Yang, Y. T., Sun, G. H., \& Zheng H. (2019). Stability analysis of soil-rock-mixture slopes using the numerical manifold method. Engineering Analysis with Boundary Elements, 109, 153-160. https://doi.org/10.1016/j.enganabound.2019.09.020

[7] Erzin, Y. \& Cetin, T. (2013). The prediction of the critical factor of safety of homogeneous finite slopes using neural networks and multiple regressions. Computers and Geosciences, 51, 305-313. https://doi.org/10.1016/j.cageo.2012.09.003

[8] Li, A. J., Khoo, S., Lyamin, A. V., \& Wang, Y. (2016). Rock slope stability analyses using extreme learning neural network and terminal steepest descent algorithm. Automation in Construction, 65, 42-50. https://doi.org/10.1016/j.autcon.2016.02.004

[9] Kohgo, Y., Takahashi, A., \& Suzuki, T. (2010). Centrifuge model tests of a rockfill dam and simulation using consolidation analysis method. Soils and Foundations, 50(2), 227-244. https://doi.org/10.3208/sandf.50.227

[10] Cao, J., Zheng, J. G., \& Zhang, J. W., (2017). Centrifuge model test of loess high fill settlement under different boundary conditions. Journal of China water resources and Hydropower Research Institute, 15(4), 256-261. https://doi.org/10.13244/j.cnki.jiwhr.2017.04.003

[11] Enomoto, T. \& Sasaki, T. (2015). Several factors affecting seismic behaviour of embankments in dynamic centrifuge model tests. Soils and Foundations, 55(4), 813-828. https://doi.org/10.1016/j.sandf.2015.06.013

[12] Boulanger, R. W., Khosravi, M., Khosravi, A., \& Wilson, D. W. (2018). Remediation of liquefaction effects for an embankment using soil-cement walls: Centrifuge and numerical modeling. Soil Dynamics and Earthquake Engineering, 114, 38-50. https://doi.org/10.1016/j.soildyn.2018.07.001

[13] Xu, M., Jin, D. H., Song, E. X., Shen, Z. P., Yang, Z. J., \& Fu, J. Y. (2019). Full-scale creep test and back-analysis of the long-term settlement of heavy-loaded shallow foundations on a high rockfill embankment. Computers and Geotechnics, 115, 1-15. https://doi.org/10.1016/j.compgeo.2019.103156

[14] Cao, W. Z., Zheng, J. J., Zhang, J., \& Zhang, R. J. (2016). Field test of a geogrid-reinforced and floating pile-supported embankment. Geosynthetics International, 23(5), 348-361. https://doi.org/10.1680/jgein.16.00002

[15] Gan, L., Shen, Z. Z., \& Xu, L. Q. (2014). Long-term deformation analysis of the Jiudianxia concrete-faced rockfill dam. Arabian Journal for Science and Engineering, 39(3), 1589-1598. https://doi.org/10.1007/s13369-013-0788-6

[16] Yu, F., Qi, J., Yao, X., \& Liu, Y. (2013). In-situ monitoring of settlement at different layers under embankments in permafrost regions on the Qinghai-Tibet Plateau. Engineering Geology, 160, 44-53. https://doi.org/10.1016/j.enggeo.2013.04.002

[17] Chik, Z. \& Aljanabi, A. Q. (2014). Intelligent prediction of settlement ratio for soft clay with stone columns using embankment improvement techniques. Neural Computing and Applications, 25(1), 73-82. https://doi.org/10.1007/s00521-013-1449-0

[18] Sukkarak, R., Pramthawee, P., \& Jongpradist, P. (2017). A modified elasto-plastic model with double yield surfaces and considering particle breakage for the settlement analysis of high rockfill dams. KSCE Journal of Civil Engineering, 2l(3), 734-745. https://doi.org/10.1007/s12205-016-0867-9

[19] Zhu, C. H., Li, N., Liu, M. Z., \& Wei, Y. F. (2013). Spatial and temporal analysis of post construction settlement of 
loess high fill foundation at Lüliang Airport. Chinese Journal of Geotechnical Engineering, 35(2), 293-301.

[20] Miščević, P. \& Vlastelica， G. (2019). Estimation of embankment settlement caused by deterioration of soft rock grains. Bulletin of Engineering Geology and the Environment, 78(3), 1843-1853.

https://doi.org/10.1007/s10064-017-1203-4

[21] Zhang, X. X., Zhang, J. M., \& Wen, Y. F. (2015). Practical calculation method for subgrade settlement under long term traffic load. Chinese Journal of Geotechnical Engineering, 37(11), 2067-2072. https://doi.org/10.11779/CJGE201511018

\section{Contact information:}

Yanqing ZHANG, PhD

1) School of Civil Engineering and Architecture, Xi'an University of Science and Technology,

2) Road Engineering Research Center, Xi'an University of Science and Technology,

No. 58 Yanta Road, Xi'an 710054, Shaanxi Province, China

E-mail: zhangyq@xust.edu.cn

\section{Hongjun JING, Prof.}

(Corresponding author)

1) School of Civil Engineering and Architecture, Xi'an University of Science and Technology,

2) Road Engineering Research Center, Xi'an University of Science and Technology

No. 58 Yanta Road, Xi'an 710054, Shaanxi Province, China

E-mail: jinghongjun@xust.edu.cn

\section{Jun DAl, Prof}

School of Civil Engineering and Architecture,

Xi'an University of Science and Technology,

No. 58 Yanta Road, Xi'an 710054, Shaanxi Province, China

E-mail: rockblasting@xust.edu.cn

\section{Shun-fei LI, Senior engineer}

Ankang Traffic Engineering Test \& Inspection Co., Ltd

No. 8 Chaoyang Street, Ankang 725000, Shaanxi Province, China

E-mail: lishunfei@163.com

Zhong ZHANG, Senior engineer

Wuding Expressway Management Office of Shaanxi Communications

Construction Group Corporation

No. 6 Tangyan Road, Xi'an 710075, Shaanxi Province, China

E-mail: 2247555610@qq.com 